\title{
Telecentres for sustainable rural development: Review and case study of a South African rural telecentre
}

\section{Marthinus C Breitenbach ${ }^{1}$}

This paper evaluates a South African rural telecentre that may serve as a 'best practice' model. The paper first provides a brief literature review of telecentres and the role of information and communication technology in economic development. A qualitative evaluation of a case study is presented within the context of sustainability considerations and development outcomes; that is, showing how the telecentre has improved the lives of the rural community at Thabina. Some of the observed economic development impacts are listed in the paper and an attempt is made to capture the essence of the vital links between the use of information and communication technology (technology transfer), human development, education and economic development.

Keywords: telecentres; development communication; information and communication technology; human development; rural livelihoods; rural development

JEL codes: O 014; O 015; O 018

\section{Introduction}

Telecentres have been with us for a long time and are a highly underestimated tool of integrated local economic development, rural development, economic empowerment and socio-economic development in general.

The author firmly believes that research and policy recommendations often neglect service delivery and service delivery mechanisms, such as telecentres, especially in Africa. A comprehensive review of the role of telecentres in economic development lies beyond the scope of this paper. The paper provides only brief definitions and background in regard to telecentres because its focus is on the case study. Although not explicitly argued in this paper, telecentres and other forms of information and communication technology (ICT) have not gained their rightful place in public-sector policy and programmes, and neither has their role in development and public sector economics been adequately outlined.

The aim of the paper is to inform policy-makers in South Africa and Africa of, first, sustainability considerations that render telecentres successful for economic development, and, second, the observed positive improvements (development outcomes) in lives of the rural community at Thabina. The author believes the evaluation of the processes that were followed can be of value for the drafting of specific programmes, and that evaluation of the extent to which development outcomes were achieved contributes to policy debates in South Africa and Africa.

The paper unfolds as follows. Telecentres are first defined and their role in economic development, as described in the literature, briefly stated. Section 4 takes a fresh look 
at the vital links that exists between telecentres (which house ICT) and economic development via the human development cycle. Section 5 briefly looks at some of the existing telecentres in South Africa and points out that the literature survey could not deliver a single example of a successful South African telecentre (as measured against sustainability criteria). This implies the need for a workable and sustainable 'best practice' telecentre model to serve as a blueprint for using telecentres to facilitate successful and sustainable economic development.

Section 6 presents the evaluation of a case study of a rural telecentre. This is done by outlining the phases and actions followed in setting up the telecentre at Thabina and the telecentre's key assumptions and objectives. The degree to which the key assumptions and objectives were met serves as a yardstick for the sustainability of the telecentre and its successes in achieving economic development outcomes.

\section{Defining telecentres}

There is an ongoing problem with defining telecentres as so many related terms are used with varying meanings. Colle \& Roman (1999) counted over 30 different names for these kinds of centres. Some are detailed in this sub-section.

Public access is a key feature in definitions. Colle \& Roman (1999) suggest that a telecentre is a shared facility that provides public access to ICTs. Kanfi \& Tulus (1998) from the Canadian International Development Research Centre (IDRC) define a telecentre as: 'A location which facilitates and encourages the provision of a wide variety of public and private information-based goods and services, and which supports local economic or social development'. Community ownership is another important feature. Cisler (1998) proposes that 'A telecentre provides information and communication services needed by the local community'.

Analysts also stress aspects of development. For example, according to Zongo of the IDRC's Acacia programme in Africa, a telecentre 'is a place where public access to communication and information for economic, social and cultural development is provided' (Zongo, 1999). In Africa, services at centres are of the highest priority. Telecentres may simply be defined as various kinds of strategically located facilities providing public access to ICT-based services and applications.

While there is no single definition of a telecentre to satisfy everyone, a common characteristic is a physical space that provides public access to ICTs for educational, personal, social and economic development.

\section{The importance of telecentres for development}

Telecentres have been hailed as one of the most promising solutions to development problems around the world due to their ability to provide desperately needed access to ICTs (Gòmez et al., 1999). A significant number of such centres have been piloted and implemented by various governmental and development agencies across the globe (Latchem \& Walker, 2001). In the discussion below, these centres receive special attention.

There are now many funded projects establishing larger telecentres throughout Africa. The main programme has been a partnership between the ITU, the UN Education, 
Scientific and Cultural Organization (UNESCO) and the IDRC that has established major centres in Mali, Uganda, Mozambique and South Africa.

The Food and Agricultural Organisation had claimed already in 1987 that:

People refer to newer insights on the role and place of communication for development, which favours two-way and horizontal communication and techniques to increase people's participation in development and to inform, motivate and train the rural population, mainly at the grass-roots level. (Lazerfeld et al., 1994:151)

People need and want to be informed in order to be able to take part in their own development - to become part of the information society.

Benjamin \& Dahms (2001) conclude that telecentres could serve to mitigate exclusion in a rural community. With the exclusionary effects of global informational capitalism, the primary line of division is between the rich northern countries and poorer countries of the south. However, there is also division between the elites and the poor in most countries.

The question that should be asked at this point is how exactly ICT enters the economic development sphere. The next section explores the links between ICT and economic development from a theoretical perspective.

\section{Development economics within the context of African human development and the role of $\mathrm{ICTs}^{2}$}

\subsection{Vital links}

It makes little sense to discuss economic development and the role of ICTs in isolation. This is particularly true in Africa where a holistic approach is essential if one is to understand the interrelated roles of culture, social relations, communication and other factors in development. The links between technology transfer, education and training, and human development are therefore briefly outlined here.

Sceptics often ask, and sometimes rightly so, how strange western technologies such as ICTs, and in particular telecentres, can be transplanted into Africa with any degree of success. It is necessary to take an expanded view of economic and human development to both understand and successfully apply ICTs in development.

\subsection{Linking education and technology to development}

It is postulated that there are two causal relationships of value in human development. The first relationship runs from technology transfer to human development to improved education and, ultimately, to economic development. It is the individual who learns new technology when it is introduced (transferred) to the individual. The recipient's knowledge (and learning capacity) is enlarged and therefore human capacity built when internalising this technology. The second is the causal relationship that runs from education to human development, which leads to a higher technology absorption rate and ultimately leads to more economic development. Each time that human development is achieved, economic development is achieved by definition.

${ }^{2}$ The role of ICTs in development and especially in the lifecycle of learning hypothesis is more fully covered in Malan \& Breitenbach (2005). 
Lastly, it is argued that these two causal relationships work in the same direction and therefore reinforce each other. This is illustrated in Figure 1. The use of technology (specifically ICTs) reinforces education by making education more accessible and by developing human cognitive ability with technology transfer; improved education again increases human cognitive ability to absorb more technology transfers. This can be referred to as a continuous process, as a lifecycle of learning that can be described as the ongoing learning and education experience of an individual throughout his or her productive life.

Improved education leads to more technology being internalised, leading to more education and improved learning (a human factor capacitated through the internalisation of technology - 'technolofied human' - acquires improved cognitive skills), building human capacity in a cumulative fashion and having the potential to accelerate economic development. The interaction of the two causal relations described brings forth the potential for exponential human development: 'this phenomenon of accelerated human capacity brought on by an explosion in the supply of information and communication will come to characterise $21^{\text {st }}$ century economic development' (Breitenbach, 2005).

\section{Existing telecentre offerings}

Contrary to the situation in developing countries, telecentres in Africa are often located in rural communities. This aspect will be surveyed first. The telecentre provides the

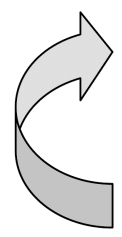

Education enhances cognitive ability that reinforces the rate of technology transfer

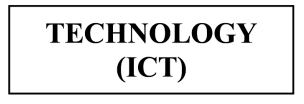

Technology transfer spurs human development
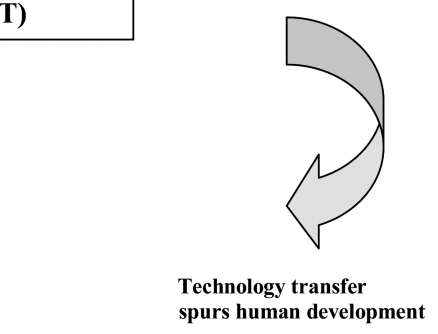
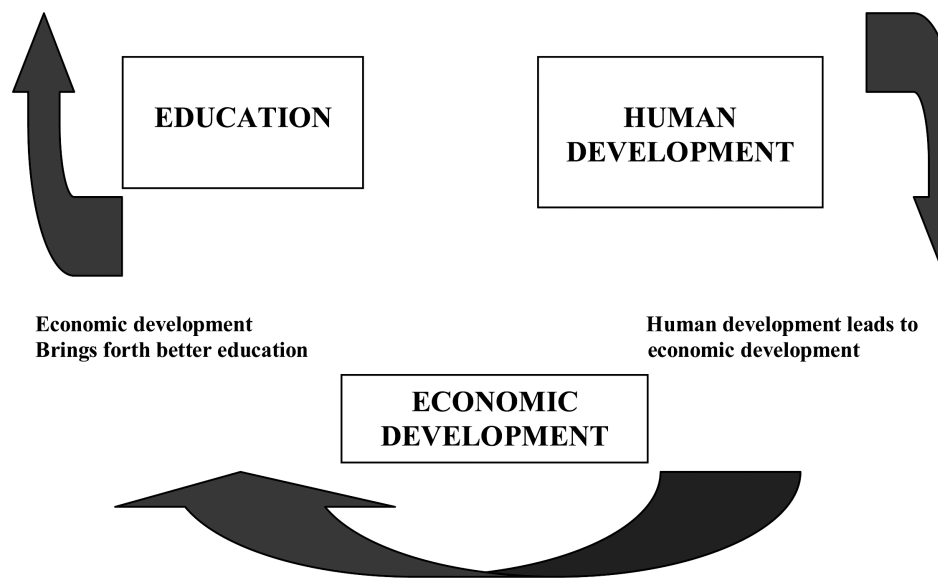

Figure 1: Human development cycle and technology transfer 
necessary infrastructure such as ICTs, which are tools to provide the information or content to address the information needs of a specific community. Currently in Africa there are numerous disadvantaged communities, particularly in rural areas. They are in desperate need of social and economic empowerment. A contributing factor to their situation is the absence of the necessary infrastructure to support information and communication, which again support development. The empowerment of communities is a major development goal in itself. In addition, the telecentres provide basic development tools, particularly for youth development.

The necessity for various forms of centres and applicable ICTs is recognised worldwide, with Africa no exception. Today, the number of telecentres - some of them equipped with only a telephone and a fax machine, and others with computers, printers and an Internet connection - is mushrooming all over Africa: 'They are springing up everywhere', says Zongo (1999): 'We have counted 9,000 of them just in Senegal, in West Africa, where they have opened job opportunities to some 20,000 people within the last five years'.

The limited number of case studies on telecentres in Africa indicates that these centres are by no means all success stories. Major problems are the lack of continued sustainability and donors, as well as poor managerial and administrative skills. For technology transfer to develop local ability and function successfully, the capacity and strength of the recipient organisation to negotiate with the donor organisation is a key requirement, according to Benjamin \& Dahms (2001). They continue that in many cases technology transfer has led to either failure (the system not working and money wasted) or to dependency (system working but increased reliance on donors and suppliers).

Since South Africa is the African country with by far the most sophisticated telecentre networks and available research on telecentres, it is in the spotlight so far as models and case studies are concerned. In addition, the South African government has funded and erected a number of multi-purpose community centres with the main aim of bringing basic government services and information to communities. The official headcount of telecentres that Comtask (2003) classifies as multi-purpose community centres puts their total number in South Africa as 69.

The following section provides a summary report of the successful telecentre at Thabina in the Limpopo province of South Africa.

\section{Case study: Thabina telecentre project ${ }^{3}$}

\subsection{Reasons for selecting Thabina as useful research focus for a rural telecentre}

The Thabina community is situated about 30 kilometres outside Tzaneen on the Lydenburg road in the Limpopo province of South Africa. Thabina is a rural farming community with about 150 black farmers cultivating some 230 hectares of irrigation land. Maize is produced in summer and vegetables in winter. There are several reasons why the Thabina community was considered a good choice to establish a rural pilot telecentre for observation and study. These are briefly as follows:

${ }^{3}$ Most of the section appears in a comprehensive case-study paper by van der Merwe et al. (2006). 
- Rural communities are traditionally oriented towards agriculture. The Limpopo province is one of the provinces with the largest rural population relative to its total population.

- The Thabina irrigation scheme forms part of the erstwhile Lebowa homeland and is one of 171 irrigation schemes formerly developed in the province. It was the first and only small-scale irrigation scheme to become a water user association (WUA) in terms of the National Water Act (Act 36 of 1998). The Thabina irrigation scheme has certain delegated functions in terms of this act and could obtain a subsidy from the Department of Water Affairs and Forestry for bulk infrastructure such as a dam, canals and weirs.

- The community appeared to need information on farming practices and to communicate with other agriculture-related organisations. It was therefore the ideal community to research in terms of the effectiveness of ICTs in a rural context, from the planning stages of the telecentre through to evaluating the economic impact on rural development after initiation of the pilot centre.

\subsection{Objective of the case study}

This case study explores the proposition that to promote sustainable rural agricultural development the provision of basic development information and communication is a necessary but not sufficient condition. Development ICT is delivered via a telecentre. Hence, the telecentre needs to be evaluated for sustainability and the successful achievement of development outcomes in the community it serves.

Sustainability requires that the community continues with the telecentre once the donors withdraw from the project. This implies that the processes followed in setting up the telecentre are completely driven by the community's need for development information and communication and that the community participates in every decision and during each phase of the development of the telecentre, including its use, maintenance and management.

The case study covers the patient and committed preparatory actions taken prior to setting up the telecentre at Thabina and evaluates the extent to which it was successful in meeting significant local information and communication needs and the sustainability of the outcomes that were generated. The preparatory actions taken are briefly listed and outlined in the sub-sections that follow.

\subsubsection{The pre-development phase}

During a first meeting in January 2001 with the 12 members of the management committee of the WUA, a strong need to communicate with other WUAs as well as with agriculture-related organisations such as the Department of Agriculture, the Limpopo Department of Agriculture and others was expressed. It also became clear that members needed to improve substantially their financial management system for monthly payments and related bookkeeping and reporting.

- Action 1: Official approval to implement the pilot project. Before the pilot project could commence, the approval of the director of the policy and planning unit of the then Northern Province Department of Agriculture, currently the Limpopo Department of Agriculture, had to be obtained. This was because the water distribution infrastructure, in this case a weir and a five kilometre canal, was owned and managed by the Limpopo Department of Agriculture. 
- Action 2: Identifying the practical on-the-ground basic needs of the community. The practical basic needs of the Thabina agricultural community were investigated through an in-depth survey conducted by independent consultants, and presented earlier. This survey identified key needs, problems, fears and aspirations, referred to as the 'NPFA' in the study.

- Action 3: Researching the community's main information needs. Establishing the specific information needs of the Thabina community was based on the above NPFA study. It is of cardinal importance because the tendency of many donor agencies to invest in multimillion dollar projects without making a systematic effort to investigate and understand the real information needs of the local people has too often been a major reason for disillusionment, disappointment and failure (Agunga, 1998; Hammer, 1994).

- Action 4: Summary of the information needs obtained. The description of the NPFAs as identified by the community, followed by the associated information needs and the ICT necessary to address the needs, are summarised in Table 1.

- Action 5: Explaining ICT to the management committee. The management committee had no prior knowledge of either the Internet or ICT. Thus, during a special workshop, the ICT concept, the computer and the many practical implications involved were carefully explained to the committee, often with the help of sketches made beforehand. A translator was used throughout to ensure effective communication with the locals who spoke Pedi and Tsonga.

The above process of patient and participative information sharing and free exchange also established a valuable relationship of trust, which is regarded as essential for the eventual success of a local telecentre.

\subsubsection{The subsequent preparatory actions phase}

- Action 6: Addressing major outstanding issues, including obtaining support from the local farmers. Further management committee meetings were organised to discuss two major outstanding issues: the project plan to establish a telecentre, and the practical question of managing the telecentre effectively.

It was agreed that wider participative grassroots consultation was necessary for greater community support. It was further agreed that effective communication would require compiling a questionnaire to be completed through structured personal interviews with local farmers. The main objective was to obtain basic needs and, ultimately, to establish whether a telecentre was the ideal solution. Although the questionnaire was translated into Tsonga, the respondents did not have to be literate as the questions were explained to them in their home language. These steps contributed greatly to explaining clearly what was required of the participants; their indigenous culture was taken into account in a committed manner.

The questionnaire contained two sections: demographics, and current exposure to and specific needs for ICT. Some of the main results obtained were as follows:

- $95 \%$ of the farmers received their income from full-time farming; $60 \%$ of the farmers' spouses had full-time jobs;

- $25 \%$ of the farmers had no formal schooling, which meant they were basically illiterate; 


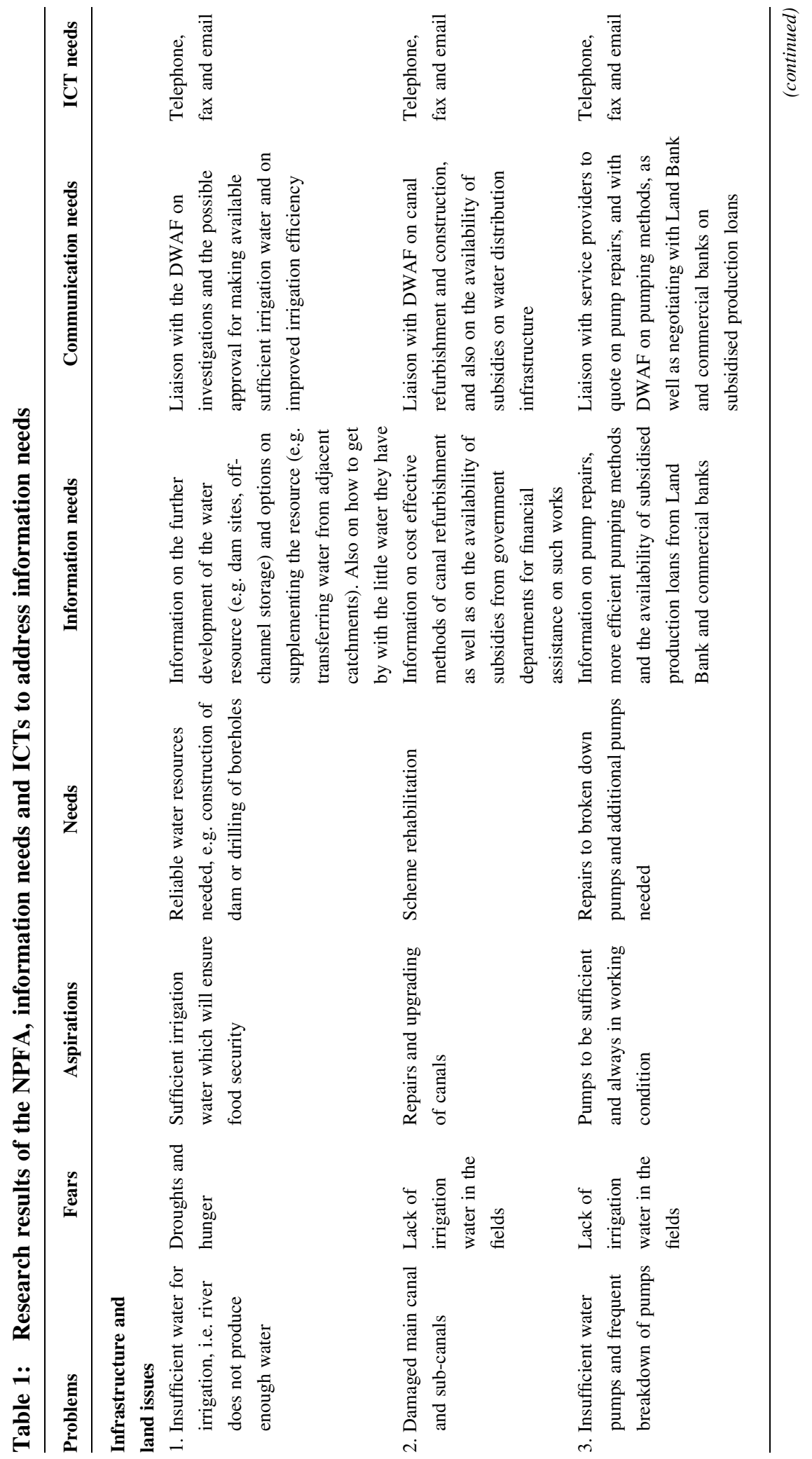




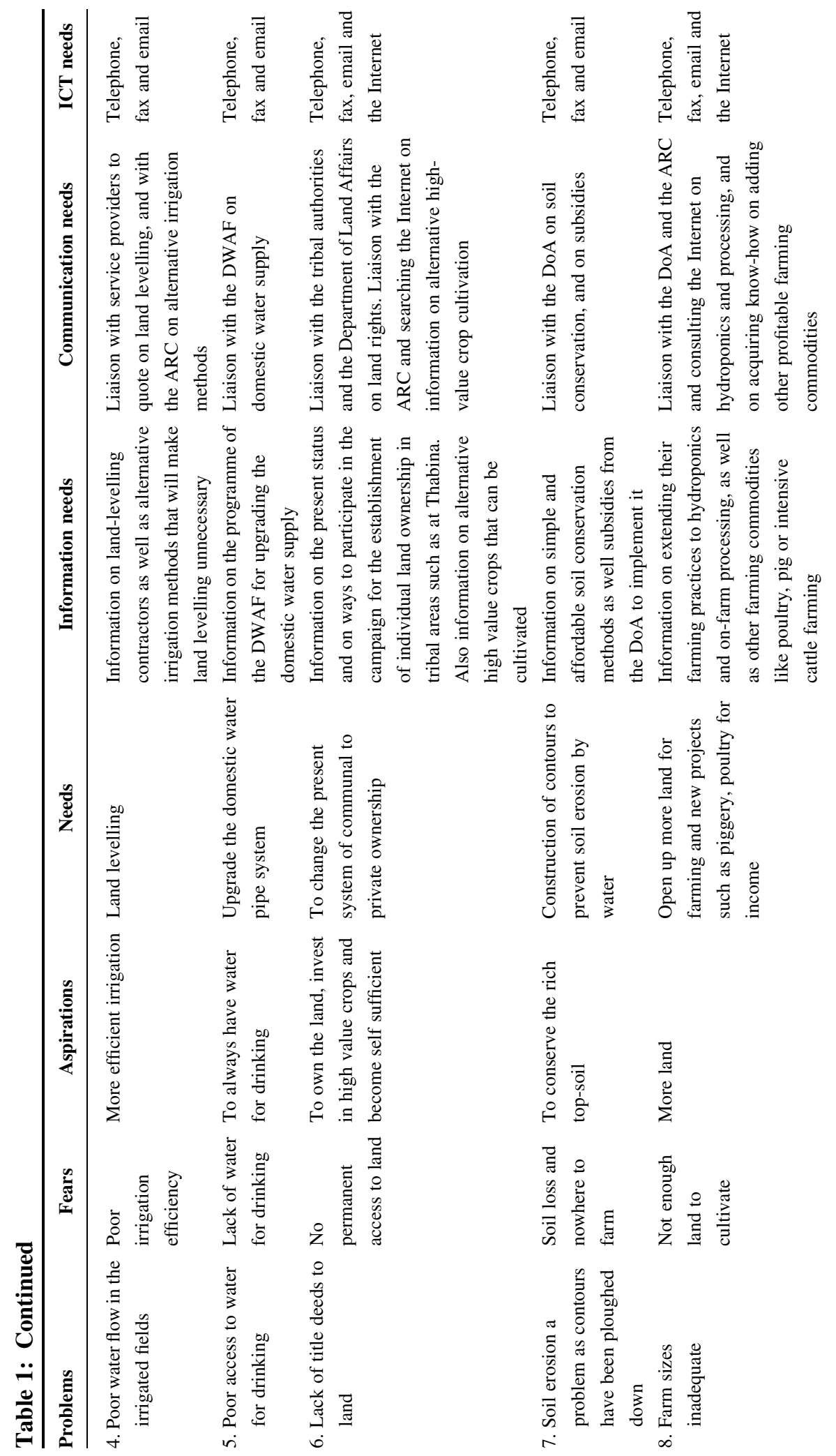




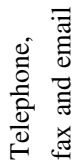

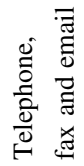

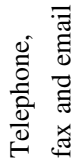

पे $\frac{0}{2}$

:

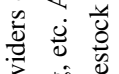

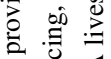

氖

造吉

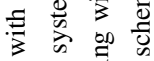

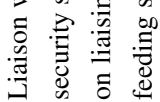

골요

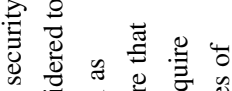

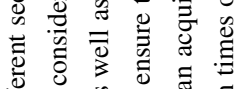

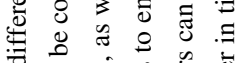

б ह

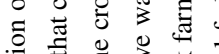

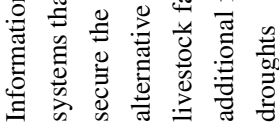

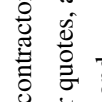

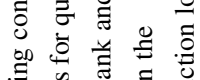

表贻

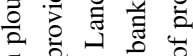

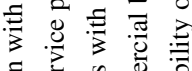

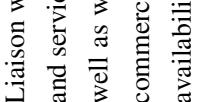

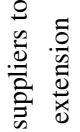

志

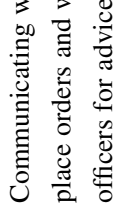

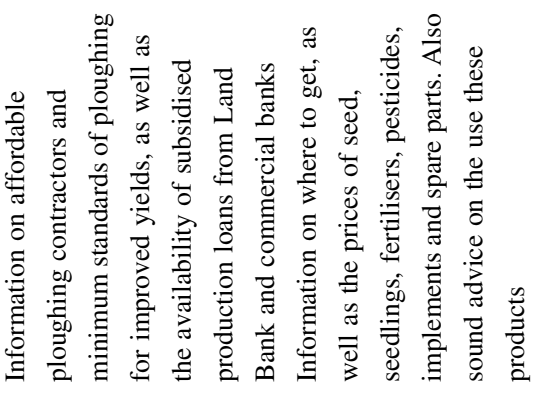

旁
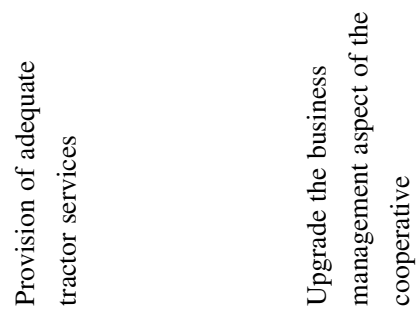

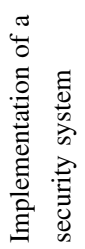

受

产

产

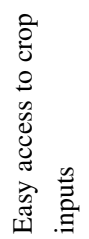

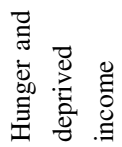

$\frac{5}{20}$

产

范

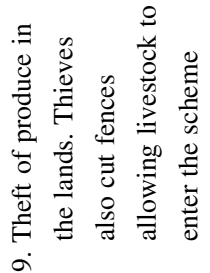

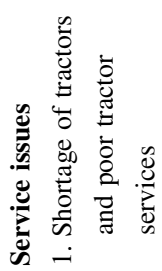

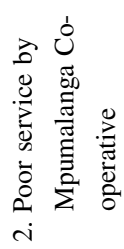




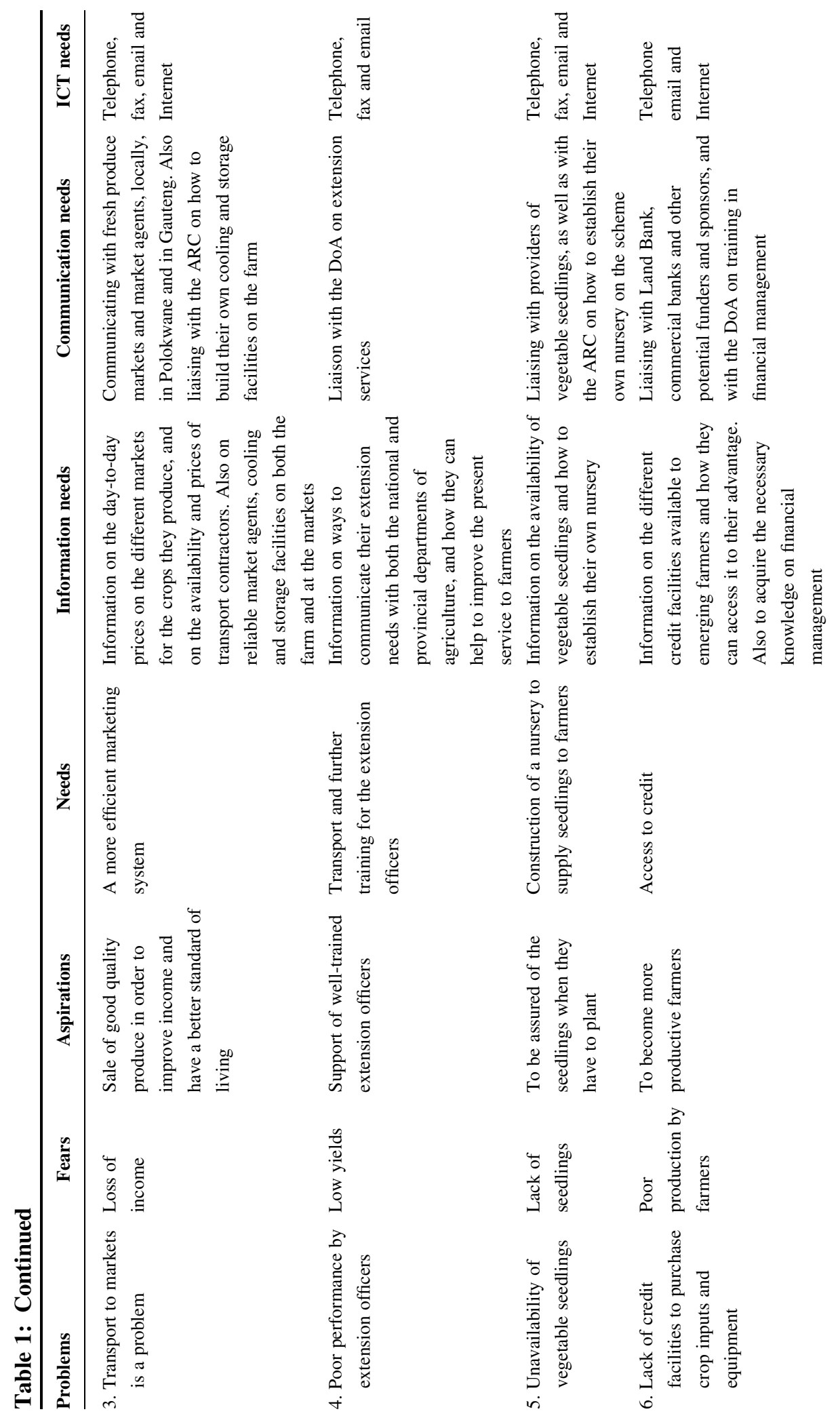




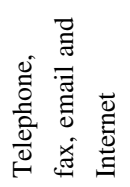

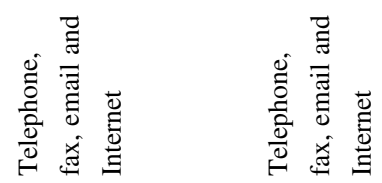

ธี

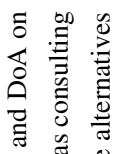

峎

$\stackrel{2}{\Xi}$ i

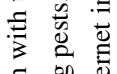

范

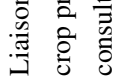

.]

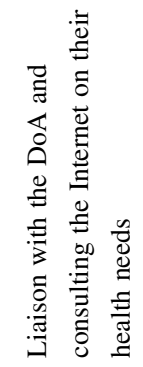

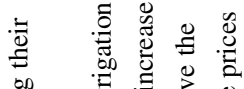

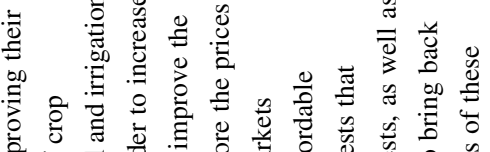

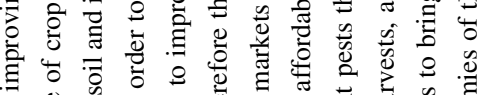

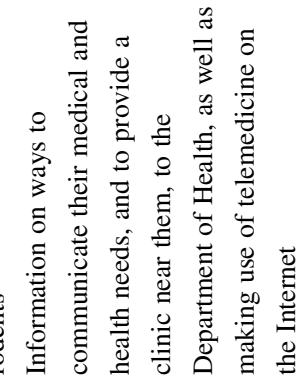

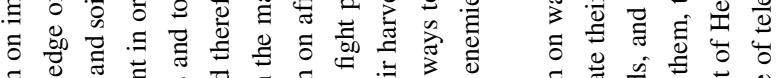

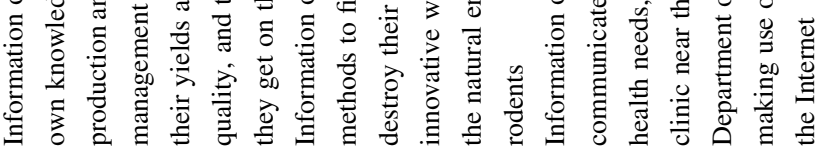

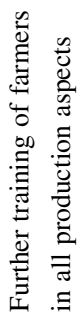

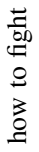

苨

छ̊.

营

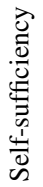
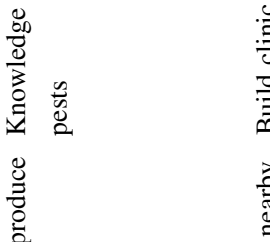

学

일

잉

วั

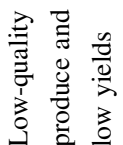

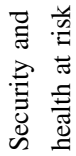

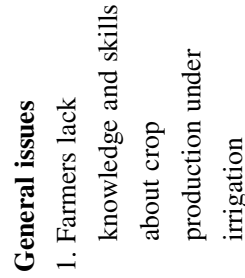

$\begin{array}{ll}\text { पे } & 0 \\ 0 & 0 \\ 0 & 0\end{array}$

$\stackrel{0}{7}$

$\circ$

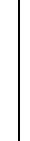

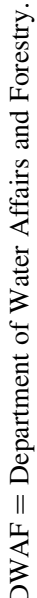

兽

4

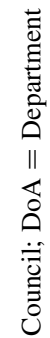

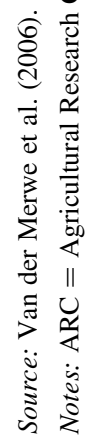

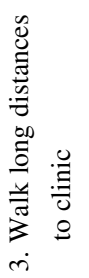


- only $18 \%$ of the farmers had a telephone at home but $98 \%$ had a telephone at work this indicated that the farmers could make good use of a telephone facility at the telecentre;

- the farmers had little exposure to ICT but would welcome such an opportunity, especially if it was provided in an 'office' like a telecentre to which they would have ready access - they needed help with their farming practices, with improving their working conditions and with obtaining useful agricultural information;

- all of the farmers were willing to pay a nominal fee for using the telecentre;

- most of the farmers would like to tell the people outside their community what they were doing, what they were selling, and about their own culture - this interest showed that an own website could usefully be introduced at some stage;

- a computer would be used mainly to obtain information on farming, to correspond with other agriculture-related organisations and for word processing - however, social aspects such as health, education and job creation were also regarded as important; and

- $94 \%$ had to travel to other villages to access ICT and would have to travel much less if they could use a telecentre inside their own community.

\subsection{Setting up the telecentre}

To be brief, the telecentre was established with the following ICT elements (identified during the NPFA as ICT needs):

- a telephone facility to provide access to all;

- a new personal computer, to be used mainly for word processing and to computerise the bookkeeping system of the local WUA;

- a new copier-fax-printer-scanner; and

- a small library.

Internet and e-mail facilities would be obtained only when more funds were available. Through participative decision-making, it was decided that the above items would be bought on a 50/50 basis, as this would support the community taking ownership of the ICTs. External donors were found to fund the rest.

\subsection{Sustainability considerations}

This section addresses the sustainability issue. Is the telecentre self-sustainable? To what extent has it contributed to sustainable agricultural development in the community? Generally, sustainability implies the ability to continue into the future for a long time substantially as is; that is, without serious disruption forcing drastic changes.

The researcher evaluated the telecentre inter alia according to whether the operational assumptions made at the beginning proved to be accurate and whether the objectives of the project were attained. The evaluation in terms of the key assumptions follows in Section 6.5; first, however, the key assumptions and the objectives of the project that were evaluated are briefly listed.

\subsubsection{The key assumptions}

Community ownership can be obtained through effective participant communication especially by means of patient, focused and substantial stakeholder involvement. It is regarded as an essential condition for attaining sustainability. 
Evaluation: This approach, in accordance with the basic DSC paradigm, was implemented from the beginning. Indeed, a comprehensive and endogenously based communication strategy was seen as a vital component of the whole project.

Anonymous testimony to the success of the participative communication approach was received from the community.

\subsubsection{Particular information needs must be identified and prioritised beforehand.}

The choice of the particular ICT elements that would be most useful to the local community was based on a study to identify and prioritise the practical information needs of the farmers.

Evaluation: As per the discussion of Table 1, appropriate ICTs were identified to address the particular information and communication needs. Priority was given to buying a computer mainly to computerise the bookkeeping system of the WUA - a major development need. In addition, a small but highly farming oriented library facility was approved.

\subsubsection{Managing the telecentre well requires much preparatory work}

Evaluation: Extensive guidelines on how to operate and run the telecentre were drawn up by the researcher and discussed at length with the management committee (and the newly appointed secretary). Suitable training courses were also decided on and arranged. The subsequent satisfaction expressed by the management of the telecentre bears testimony to the validity of this assumption.

\subsubsection{Objectives of the project}

- Access to ICT infrastructure is to be provided.

Evaluation: This was achieved in so far as new telephone facilities, a computer and a fax-copier-printer-scanner were installed for use by the community.

- Useful community information and communication services are to be established.

Evaluation: The farmers and their families use the telephone regularly. The library provides most of the information on farming practices which the farmers were looking for. The fax made a large contribution to communication where particular information (e.g. prices) had to be obtained. The computer, apart from providing an often-used private word processing service, made a notable contribution to the efficient financial management of the WUA's irrigation scheme, acknowledged and emphasised by all the farmers.

- Establishing a sustainable telecentre

Evaluation: The farmers agreed to increase their levies to fund the telecentre, which augurs well for financial sustainability. The new computerised bookkeeping system has brought about the realisation that expert external assistance to improve local farming practices (and hence their financial position) is urgently needed. In addition, the telecentre is promoting the social development of the community. The community now has a library, receives one newspaper and the journal of the Department of 
Agriculture free of charge, obtains lectures and workshops on health matters (especially HIV and AIDS) and all the children have been vaccinated. It thus seems highly likely that the telecentre will continue to operate usefully for a long time to come; that is, it is indeed sustainable.

\subsection{Case-study findings}

In this study the focus is on the successful establishment of a rural telecentre. Clearly, to be deemed successful a telecentre must continue operating long after the initial set-up phase has been completed and any initial support, financial or otherwise, has been withdrawn. South Africa does not at present have any 'best practice' model to which it can refer should it wish to establish telecentres for development. The only other model of its kind that could be found over the period of the research, which in total exceeded four years, failed to continue after financial and other support was withdrawn.

During the duration of the study all relevant literature was studied for 'best practice' sustainability guidelines and advice. These were carefully documented and adapted to local circumstances. The end result was a rural telecentre that was established along strict guidelines. For the process to work, especially in a marginalised rural community with a low level of literacy, much dedication and patience is required. It may be stated in no uncertain terms that it is a disadvantage of this and any other development effort of significance; it is a slow and laborious process.

If the whole process is analysed for its success, the first question is whether the process attained its goals. With respect to the first goal, namely that of successfully and painstakingly following 'best practice' guidelines and prescriptions, the answer is an overwhelming yes.

When evaluated against the backdrop of the basic needs of the community in terms of development information and communication, two questions come to mind. First, was the appropriate technology identified to fulfil the need? Second, was the developing rural community able to use the appropriate information and communication technology to its benefit? Again, the study indicated that, in regard to both these questions, the processes that were established and implemented achieved the desired results.

Next, and although not the intended purpose of the study, were any economic or socio-economic development outcomes achieved? Early in the paper it is argued that development information and communication is an important ingredient of economic development. An evaluation of the extent to which the telecentre at Thabina achieved its development information and communication targets indicates that these targets were achieved. This being so, it stands to reason that economic development had been achieved by definition. To add weight to this argument, the paper has shown that certain human and socio-economic development outcomes were achieved. A big step forward was the upgrading of the local WUA towards the provision of enough irrigation water to obtain better yields. The seeking of external assistance to help the locals with improved farming practices to secure a more stable financial future points in a similar direction. The new computerised bookkeeping system was the basis for expert external assistance to improve local farming practices. In addition, social development of the community includes access to a library, access to information via a newspaper and the agricultural journal, health information and vaccination of all the children. 


\section{Reported development outcomes through telecentres}

- Improved development information and communication

- Provision of education and training to remote areas

- Improved efficiency of government service delivery, especially in remote rural areas - and health service delivery in Thabina

- Increased trade and marketing opportunities, nationally and internationally

- Improved access to basic government information and services

- Increased human empowerment

- New employment opportunities

The development outcomes observed throughout this paper are summarised in Table 2.

\section{Conclusions}

This paper reviews literature descriptive of the nature, workings and applications of telecentres as a means of applying ICTs in economic development. The paper is meant to inform policy-makers and researchers in the economic and management sciences and humanities of the tremendous impact that ICTs can have on the lives of those in the developing world through telecentre applications.

The case study of Thabina indicates that establishing a successful telecentre in a rural community takes time and dedication. Success requires that a painstakingly slow but fully participative process be followed. All indications are that the telecentre will be sustainable in the long run and that it will continue to be an effective tool for bringing much-needed development information and communication to the community. It has also shown to bring immediate socio-economic benefits to the affected community. The evaluation of the telecentre's impact has shown that by meeting the development information and communication needs of the rural community of Thabina, the community is left with improved skills, access to information and education, and much-needed agricultural development information.

Two lessons may be advanced to policy-makers. First, on the design of sustainable telecentres, the phases and actions followed at the Thabina telecentre may serve as a 'best practice model' for the design of development programmes. Second, very definite socio-economic development outcomes suggest that the advancement of telecentres as a delivery mechanism of transferring technology for rural agricultural development deserves the full attention of policy-makers.

\section{References}

Agunga, RA, 1998. Communication for development in Africa - a clarion call. Communicare 17(1).

Benjamin, P \& Dahms, M, 2001. Socialise the modem of production - The role of telecentres in development. http://www.idrc.ca/Telecentre/evaluation Accessed 20 December 2001.

Breitenbach, MC, 2005. Reviewing the theoretical relationship between technology transfer through ICT, education and human development. Working Paper, University of Pretoria.

Cisler, S, 1998. Telecentres and libraries: New technologies and new partnerships. http://home. inreach.com/cisler/Telecentre.htm Accessed 13 November 2001. 
Colle, RD \& Roman, R, 1999. Communication centres and developing nations. http://www. devmedia.org/documeny/Banga.htm Accessed 15 November 2001.

Comtask, 2003. http://www.gcis.gov.za/docs/govcomm/comtask/chap5.htm

Gómez, R, Hunt, P \& Lamoureux, E, 1999. Focus on telecentres: How can they contribute to social development. http://www.idrc.ca/pan/chasqui.html Accessed 9 January 1999.

Hammer, M, 1994. Why projects fail? The FAO Review 21(1), 32.

Kanfi, R \& Tulus, F, 1998. Acacia: what is a telecentre? In Benjamin, P (Ed.), Literature Review for the Telecentre 2000 Study. . http://www.communitsa.org.za/T2000LitRev.htm Accessed 16 November 2001.

Latchem, C \& Walker, D, 2001. Telecentres: Case studies and key issues. http://www.col.org/ Telecentres Accessed 9 July 2001.

Lazerfeld, P, Berelson, B \& Gaudet, H, 1994. The People's Choice. Sloan \& Pearce, New York.

Malan, CW \& Breitenbach, MC, 2005. The role of ICTs in the economic development of Africa, with a focus on telecentres. Working paper, University of Pretoria.

Van der Merwe, D, 2003. Report on the establishment of a telecentre at Thabina. Unpublished report, University of Pretoria.

Van der Merwe, D, Van Zyl, JC \& Breitenbach, MC, 2006. Making telecentres work - a refreshing change: A case study of a successful rural agricultural telecentre at Thabina in the Limpopo province of South Africa. Working Paper, University of Pretoria.

Zongo, G, 1999. What is a telecentre? A review of best practice and models. Paper presented at the conference Building the Information Community in Africa, February. 